\title{
Complications and Socioeconomic Costs Associated With Falls in the Elderly Population
}

\author{
Yeong Guk Lee, $\mathrm{MD}^{1}$, Seung Chan Kim, $\mathrm{MD}^{1}$, Misoo Chang, $\mathrm{MS}^{2}$, Eunwoo Nam, $\mathrm{PhD}^{2}$, \\ Seul Gi Kim, $\mathrm{MPH}^{3}$, Sung-il Cho, $\mathrm{MD}, \mathrm{PhD}^{3}$, Dong Hee Ryu, $\mathrm{MD}, \mathrm{PhD}^{4}$, Sin Kam, MD, $\mathrm{PhD}^{5}$, \\ Bo Youl Choi, MD, $\mathrm{PhD}^{6}$, Si-Bog Park, MD, PhD ${ }^{1}$, Mi Jung Kim, MD, $\mathrm{PhD}^{1}$ \\ ${ }^{1}$ Department of Rehabilitation Medicine, Hanyang University College of Medicine, Seoul; \\ ${ }^{2}$ Biostatistical Consulting and Research Lab, Medical Research Coordinating Center, Hanyang University, Seoul; \\ ${ }^{3}$ Department of Epidemiology, Graduate School of Public Health, Seoul National University, Seoul; \\ ${ }^{4}$ Daegu-Gyeongbuk Regional Cancer Center, Kyungpook National University Medical Center, Daegu; \\ ${ }^{5}$ Department of Preventive Medicine, Kyungpook National University School of Medicine, Daegu; \\ ${ }^{6}$ Department of Preventive Medicine, Hanyang University College of Medicine, Seoul, Korea
}

Objective To explore the incidence, characteristics, complications and socioeconomic impacts associated with falls in community-dwelling elderly.

Methods From September 1, 2015 to October 12, 2015, a questionnaire-based survey was conducted involving a total of 2,012 elderly who lived in Guro-gu (Seoul), Yeongdeungpo-gu (Seoul), Yangpyeong-gu (Gyeonggi-do), Dalseong-gu (Daegu), and Jung-gu (Daegu). The subjects were interviewed using a structured questionnaire to obtain demographic characteristics and comprehensive falling histories. The socioeconomic cost related to falls was estimated using the statistical data provided by the Health Insurance Review and Assessment Service.

Results Falls were recorded in 666 out of the 2,012 subjects (33.1\%) during the past year. Frequent falls occurred during December, in the afternoons, when the floor was slippery. The most common injuries included the low back and the most common injury type was sprain. The total direct costs related to falls involving the 2,012 subjects were 303,061,019 KRW (Korean won). The average medical cost related to falls in the 2,012 subjects was 150,627 KRW and the average medical cost of 666 subjects who experienced falls was 455,047 KRW. Estimates of the total population over the age of 60 years showed that the annual direct costs associated with falls in Korea over the age of 60 years were about 1.378 trillion KRW.

Conclusion This study was conducted to explore the incidence, characteristics, complications, and socioeconomic impacts of falls in community-dwelling elderly. This study is expected to be used as a source of basic data for the establishment of medical policy for the elderly and the development of a fall prevention program for the elderly in Korea.

Keywords Accidental falls, Socioeconomic factors

Received May 16, 2017; Accepted June 22, 2017

Corresponding author: Mi Jung Kim

Department of Rehabilitation Medicine, Hanyang University College of Medicine, 222-1 Wangsimni-ro, Seongdong-gu, Seoul 04763, Korea. Tel: +82-22290-9353, Fax: +82-2-2282-0772, E-mail: kimmjreh@hanyang.ac.kr

ORCID: Yeong Guk Lee (http://orcid.org/0000-0001-9244-0342); Seung Chan Kim (http://orcid.org/0000-0001-7625-0848); Misoo Chang (http://orcid. org/0000-0002-9535-7226); Eunwoo Nam (http://orcid.org/0000-0001-5175-7095); Seul Gi Kim (http://orcid.org/0000-0001-5530-0367); Sung-il Cho (http:// orcid.org/0000-0003-4085-1494); Dong Hee Ryu (http://orcid.org/0000-0002-2860-8849); Sin Kam (http://orcid.org/0000-0002-5424-3820); Bo Youl Choi (http://orcid.org/0000-0003-0115-5736); Si-Bog Park (http://orcid.org/0000-0001-8910-2262); Mi Jung Kim (http://orcid.org/0000-0003-2920-9900).

(c) This is an open-access article distributed under the terms of the Creative Commons Attribution Non-Commercial License (http://creativecommons.org/ licenses/by-nc/4.0) which permits unrestricted noncommercial use, distribution, and reproduction in any medium, provided the original work is properly cited. Copyright () 2018 by Korean Academy of Rehabilitation Medicine 


\section{INTRODUCTION}

A fall is a sudden, unintentional change in position that causes a person to move quickly downwards onto or towards the ground. The frequency of falls is increasing with age, and it is known that about a third of the elderly population aged 65 years or older and about half of those aged 80 years or older experience a fall in one year [1].

The elderly are at a greater risk of falling and sustaining injuries than younger individuals, and associated complications are also more severe than in the younger generations [2]. In the elderly, fractures of the hip, waist, wrist, and femur are occasionally caused by falls, and about $80 \%-90 \%$ of hip fractures are known to be triggered by falls [3]. In addition to physical impairment, falls affect emotions, leading to functional limitations and impairment [4].

In the elderly, falls are an important risk factor associated with quality of life and do not affect individuals alone. Korea has entered an aging society with an elderly population exceeding $7.1 \%$ of the total population in 2000 and is expected to enter an aging society in 2018. As the elderly population soars, socioeconomic losses including medical costs due to falls will continue to increase. In other words, in an aging society such as Korea, falls in the elderly represent a major challenge at the individual and social levels.

Despite studies involving the elderly falls in Korea, comprehensive studies including complications and socioeconomic impacts related to falls are lacking. In the present study [5], we investigated the current state of falls and the associated socioeconomic cost among the elderly population in rural areas. However, the limitation related to the exclusion of elderly populations in more diverse regions. Thus, this large-scale survey was planned to explore the incidence, characteristics, complications and socioeconomic impacts of falls in community-dwelling elderly.

\section{MATERIALS AND METHODS}

\section{Participants}

The questionnaires were used to survey 2,012 elderly people aged over 60 years who visited public health centers. Approximately 400 elderly people were recruited from each of the following districts: Guro-gu (Seoul),
Yeongdeungpo-gu (Seoul), Yangpyeong-gu (Gyeonggido), Dalseong-gu (Daegu), and Jung-gu (Daegu). The study included individuals from different cities and rural areas.

\section{Study methods}

This study was conducted using a questionnaire. Our previous studies reviewed and compared the existing literature related to falls in the elderly. In addition, we developed our own questionnaire and evaluated the fitness of the questionnaire in a pilot study.

From September 1, 2015 to October 12, 2015, a questionnaire-based survey was conducted involving 2,012 elderly who lived in the five areas mentioned above. The subjects were interviewed using a structured questionnaire to obtain demographic characteristics and detailed falling histories including falling rates over lifetime and during the past year, time and place of fall, causes, fallrelated injuries and complications, medical treatment and expenditure related to falls, and so on. In addition, the socioeconomic medical costs related to falls were estimated using the statistics provided by the Health Insurance Review and Assessment Service (HIRA).

\section{Medical cost estimation}

To estimate the socioeconomic costs related to falls, we obtained data based on the above survey: injury area, injury type, need for hospitalization, duration of hospitalization, need for outpatient treatment, and frequency of outpatient visits related to falls. The fall injuries were converted into the International Classification of Diseases 10th revision (ICD-10) codes by combining the area and type of injury on the questionnaire. For example, if the injury site was femur and the injury type was fracture, it was converted to $S 72$ code (fracture of femur) on the ICD-10 code.

In order to calculate the insured portion of the healthcare cost related to falls, we used the data of medical costs based on the ICD-10 codes of HIRA in 2014. Using the HIRA data, we obtained medical expense data for each ICD-10 code in Korea during 2014. However, since the ICD-10 code in the HIRA data does not exclusively include fall-related injuries, it was necessary to match the HIRA data with fall-related data on the questionnaire. The insured portions of the healthcare cost for subjects who were admitted to hospital or visited outpatient or 
Table 1. Participant demographics

\begin{tabular}{|c|c|}
\hline Variable & No. (\%) \\
\hline \multicolumn{2}{|l|}{ Gender } \\
\hline Male & 703 (34.9) \\
\hline Female & $1,309(65.1)$ \\
\hline \multicolumn{2}{|l|}{ Age (yr) } \\
\hline 60-69 & $623(31.0)$ \\
\hline $70-79$ & $978(48.6)$ \\
\hline$\geq 80$ & $411(20.4)$ \\
\hline \multicolumn{2}{|l|}{ Education } \\
\hline No education & $399(19.8)$ \\
\hline Elementary school & $741(36.8)$ \\
\hline Middle school & $401(19.9)$ \\
\hline High school & $324(16.1)$ \\
\hline$\geq$ College & $132(6.6)$ \\
\hline No answer & $15(0.8)$ \\
\hline \multicolumn{2}{|l|}{ Living arrangement } \\
\hline Living alone & $520(25.8)$ \\
\hline With family & $1,490(74.1)$ \\
\hline No answer & $2(0.1)$ \\
\hline \multicolumn{2}{|l|}{ Residential type } \\
\hline Detached house & $1,137(56.5)$ \\
\hline Apartment & $675(33.6)$ \\
\hline Villa & $195(9.7)$ \\
\hline Nursing facility & $5(0.2)$ \\
\hline \multicolumn{2}{|l|}{ Marital status } \\
\hline Marriage & $1,245(61.9)$ \\
\hline Widowed & $694(34.5)$ \\
\hline Divorced & $44(2.2)$ \\
\hline Never married & $16(0.8)$ \\
\hline No answer & $13(0.7)$ \\
\hline \multicolumn{2}{|c|}{ Subjective health status } \\
\hline Very good & $10(0.5)$ \\
\hline Good & $348(17.3)$ \\
\hline Fair & $875(43.5)$ \\
\hline Bad & $658(32.7)$ \\
\hline Very bad & $98(4.9)$ \\
\hline No answer & $23(1.1)$ \\
\hline \multicolumn{2}{|l|}{ Exercise status } \\
\hline Regular & $965(48.0)$ \\
\hline Occasionally & $460(22.9)$ \\
\hline Seldom & $574(28.5)$ \\
\hline No answer & $13(0.7)$ \\
\hline
\end{tabular}

Table 1. Continued

\begin{tabular}{|cc|}
\hline \multicolumn{1}{|c|}{ Variable } & No. (\%) \\
\hline Taking medication & $1,724(85.7)$ \\
\hline Yes & $271(13.5)$ \\
\hline No & $17(0.8)$ \\
\hline No answer & \\
\hline Number of medication & $627(36.4)$ \\
\hline 1 & $541(31.4)$ \\
\hline 2 & $323(18.7)$ \\
\hline 3 & $221(12.8)$ \\
\hline 44 & $12(0.7)$ \\
\hline
\end{tabular}

oriental clinic were calculated as follows: (number of days of hospitalization or outpatient visits on the questionnaire $) \times($ data of medical expenses per day from the HIRA).

For example, in the S72 code (fracture of femur), the total number of days spent in the outpatient clinics for femoral fractures among females was 42 days, and the outpatient medical expenses per day for the S72 code in the HIRA data was 38,021 KRW (Korean won). Therefore, the total cost incurred by women among the 2,012 subjects who used outpatient clinics for fall-related femoral fracture was $1,596,882 \mathrm{KRW}$. Thus, we estimated the medical expenditure of all the subjects based on ICD-10 code, gender, hospital admission or outpatient visit.

The healthcare cost of the uninsured portion was calculated based on the 'Survey on the Benefit Coverage Rate of National Health Insurance in 2014' of the National Health Insurance Service (NHIS).

\section{Statistical analysis}

The general characteristics of the subjects were analyzed using descriptive statistics. Based on the data from the questionnaire and HIRA, we estimated the socioeconomic costs related to falls. The statistical analysis was performed using SPSS software ver. 21.0 (IBM, Armonk, NY, USA).

\section{RESULTS}

\section{Demographic characteristics}

Women constituted $65.1 \%$ of the 2,012 subjects participating in the survey. In the age category, $48.6 \%$ ranged between 70 and 80 years. The number of individuals with 
Table 2. Fall-related characteristics

\begin{tabular}{|c|c|}
\hline Variable & No. (\%) \\
\hline \multicolumn{2}{|c|}{ Fall experience (lifetime) } \\
\hline Yes & $1,472(73.2)$ \\
\hline No & $540(26.8)$ \\
\hline \multicolumn{2}{|l|}{ Fear of falling } \\
\hline Not at all & $328(16.3)$ \\
\hline A little bit & $778(38.7)$ \\
\hline Considerably & $512(25.4)$ \\
\hline Severely & $375(18.6)$ \\
\hline No answer & $19(0.9)$ \\
\hline \multicolumn{2}{|l|}{ Behavioral restrictions } \\
\hline Not at all & $341(16.9)$ \\
\hline A little bit & $785(39.0)$ \\
\hline Considerably & $481(23.9)$ \\
\hline Severely & $385(19.1)$ \\
\hline Not at all & $20(1.0)$ \\
\hline \multicolumn{2}{|c|}{ Fall experience (last 1 year) } \\
\hline Yes & $666(33.1)$ \\
\hline No & $1,346(66.9)$ \\
\hline \multicolumn{2}{|l|}{ Fall months ${ }^{\text {a) }}$} \\
\hline January & $33(5.0)$ \\
\hline February & $32(4.8)$ \\
\hline March & $68(10.2)$ \\
\hline April & $52(7.8)$ \\
\hline May & $53(8.0)$ \\
\hline June & $60(9.0)$ \\
\hline July & $72(10.8)$ \\
\hline August & $61(9.2)$ \\
\hline September & $33(5.0)$ \\
\hline October & $58(8.7)$ \\
\hline November & $44(6.6)$ \\
\hline December & $100(15.0)$ \\
\hline \multicolumn{2}{|l|}{ Falling place $^{\text {a) }}$} \\
\hline Indoor & $165(24.8)$ \\
\hline Outdoor & $500(75.1)$ \\
\hline No answer & $1(0.1)$ \\
\hline \multicolumn{2}{|l|}{ Falling time $\mathrm{e}^{\mathrm{a})}$} \\
\hline Dawn & $33(5.0)$ \\
\hline Forenoon & 224 (33.6) \\
\hline Afternoon & $335(50.3)$ \\
\hline Evening & $54(8.1)$ \\
\hline No answer & $20(3.0)$ \\
\hline
\end{tabular}

Table 2. Continued

\begin{tabular}{lc}
\hline \multicolumn{1}{c}{ Variable } & No. (\%) \\
\hline Falling cause $^{\text {a) }}$ (duplicate response) & \\
\hline Slippery floor & $286(36.3)$ \\
Ankle sprain & $100(12.7)$ \\
Stumbling on door sill & $90(11.4)$ \\
Collision & $72(9.1)$ \\
Dizziness & $61(7.8)$ \\
Sloping road & $45(5.7)$ \\
Falling down stairs & $37(4.7)$ \\
$\quad$ Etc. & $96(12.2)$ \\
\hline${ }^{a}$ Counted only for the subjects who have had a fall expe- \\
rience for the past year.
\end{tabular}

elementary school graduation was the maximum, and those living with their family accounted for $74.1 \%$. Individuals living in a detached house accounted for $56.5 \%$ of the residential type and the number of married participants accounted for $61.9 \%$. A total of $43.5 \%$ reported normal in the perception of health status, and $48.0 \%$ performed regular exercise. Individual on medication constituted $85.7 \%$, with more than half of them treated with one or two drugs (Table 1).

\section{Incidence and pattern of falls}

Of the total 2,012 subjects, 1,472 (73.2\%) experienced falls in their lifetime and 666 (33.1\%) experienced falls in the past year (from September 1, 2014 to August 31, 2015). The falls were most common in December of the past year and occurred mostly in the afternoon. The results of overlapping responses to the reasons included: slippery floor (36.3\%), followed by ankle sprain, stumbling on door sill, and collision. When asked about the fear of falling and associated behavioral restrictions most of the participants responded: 'a little bit' (Table 2).

\section{Fall-related injuries and medical use}

Among the 666 subjects who sustained falls in the past one year, $566(85.0 \%)$ reported an injury due to fall, and $100(15.0 \%)$ reported absence of injury. Among the 566 injuries, 323 (57.1\%) underwent medical treatment, and 46 cases of admissions and 315 cases of outpatient and oriental clinic visits were reported. In terms of injury area, the low back was the most common (19.1\%), followed by wrist, hip and elbow. Based on injury type, sprains and strains were the most frequent (67.3\%) 
among the outpatients and admissions due to fracture were the highest at $65.2 \%$. Among those visiting medical institutions first, patients mostly visited outpatient clinics (56.0\%) and oriental clinics (23.8\%). In terms of treatment duration, 'less than a week' was the highest response (53.0\%) among the outpatients, and 'more than 1 week to less than 1 month' was the highest (50.0\%) among hospital admissions (Table 3 ).

Table 3. Fall-related injury and medical use

\begin{tabular}{|c|c|c|c|}
\hline Variable & $\begin{array}{l}\text { Outpatient \& oriental clinic } \\
\qquad(n=315)\end{array}$ & $\begin{array}{c}\text { Admission } \\
(\mathrm{n}=46)\end{array}$ & $\begin{array}{c}\text { Total } \\
(\mathbf{n}=\mathbf{3 6 1})\end{array}$ \\
\hline \multicolumn{4}{|l|}{ Injury area } \\
\hline Low back & $61(19.4)$ & $8(17.4)$ & $69(19.1)$ \\
\hline Wrists \& hands & $43(13.7)$ & $2(4.3)$ & $45(12.5)$ \\
\hline Hip & $30(9.5)$ & $4(8.7)$ & $34(9.4)$ \\
\hline Elbow & $25(7.9)$ & $8(17.4)$ & $33(9.1)$ \\
\hline Femur & $23(7.3)$ & $3(6.5)$ & $26(7.2)$ \\
\hline Knee & $26(8.3)$ & $0(0.0)$ & $26(7.2)$ \\
\hline Multiple & $20(6.3)$ & $2(4.3)$ & $22(6.1)$ \\
\hline Forearm & $19(6.0)$ & $1(2.2)$ & $20(5.5)$ \\
\hline Ankle \& foot & $18(5.7)$ & $0(0.0)$ & $18(5.0)$ \\
\hline Head & $10(3.2)$ & $8(17.4)$ & $15(5.0)$ \\
\hline Chest & $10(3.2)$ & $2(4.3)$ & $12(3.3)$ \\
\hline Shoulder & $7(2.2)$ & $4(8.7)$ & $11(3.0)$ \\
\hline Lower legs & $9(2.9)$ & $2(4.3)$ & $11(3.0)$ \\
\hline Face & $8(2.5)$ & $0(0)$ & $8(2.2)$ \\
\hline Etc. & $6(1.9)$ & $2(4.3)$ & $8(2.2)$ \\
\hline \multicolumn{4}{|l|}{ Injury type } \\
\hline Sprain \& strain & $212(67.3)$ & $8(17.4)$ & $220(60.9)$ \\
\hline Fracture & 48 (15.2) & $30(65.2)$ & $78(21.6)$ \\
\hline Abrasion & $39(12.4)$ & $0(0)$ & $39(10.8)$ \\
\hline Laceration & $12(3.8)$ & $0(0)$ & $12(3.3)$ \\
\hline Brain injury & $1(0.3)$ & $5(10.9)$ & $6(1.7)$ \\
\hline Dislocation & $2(0.6)$ & $2(4.3)$ & $4(1.1)$ \\
\hline Etc. & $1(0.3)$ & $1(2.2)$ & $2(0.6)$ \\
\hline \multicolumn{4}{|c|}{ First visiting medical institution } \\
\hline Outpatient clinic & $181(57.5)$ & $21(45.7)$ & $202(56.0)$ \\
\hline Oriental clinic & $85(27.0)$ & $1(2.2)$ & $86(23.8)$ \\
\hline Emergency clinic & $18(5.7)$ & $20(43.5)$ & $38(10.5)$ \\
\hline Public health clinic & $17(5.4)$ & $4(8.7)$ & $21(5.8)$ \\
\hline Dental clinic & $14(4.4)$ & $0(0)$ & $14(3.9)$ \\
\hline \multicolumn{4}{|c|}{ Treatment duration (day) } \\
\hline$\leq 7$ & $167(53.0)$ & $11(23.9)$ & $178(49.3)$ \\
\hline $8-30$ & $102(32.4)$ & $23(50.0)$ & $125(34.6)$ \\
\hline $31-90$ & $44(14.0)$ & $10(21.7)$ & $54(15.0)$ \\
\hline$\geq 91$ & $2(0.6)$ & $2(4.3)$ & $4(1.1)$ \\
\hline
\end{tabular}

Values are presented as number (\%). 
Medical expenses associated with falls

\section{Medical benefits of inpatients}

A total of 46 cases were hospitalized due to injuries associated with a fall in the past year. As shown in Table 4 , the total cost of medical benefits of inpatients was $177,740,003 \mathrm{KRW}$, including insured costs amounting to $136,904,653 \mathrm{KRW}$ and patient cost-sharing of 40,835,350 KRW. The average hospitalization cost per admission was $3,863,913 \mathrm{KRW}$, and the average patient cost-sharing per admission was $887,725 \mathrm{KRW}$. The average hospitalization cost per hospital day was $132,543 \mathrm{KRW}$ and the average daily patient cost-sharing per hospital day was 30,451
KRW. The total number of hospitalization days was 1,341 days, and the average length of hospitalization per case was 29 days. In case of hospitalization, ICD-10 codes associated with the highest treatment cost were S72 (fracture of femur), followed by S52 (fracture of forearm), S32 (fracture of lumbar spine and pelvis), S06 (intracranial injury). The total hospitalization cost involving the first four codes was $141,136,011 \mathrm{KRW}$, which accounted for $79.4 \%$ of total inpatient cost.

\section{Medical benefits of outpatient clinic}

There were 230 cases undergoing outpatient treat-

Table 4. Medical benefits of inpatients according to ICD-10 codes (falls)

\begin{tabular}{|c|c|c|c|c|c|c|}
\hline \multirow[b]{2}{*}{ ICD-10 } & \multirow[b]{2}{*}{ Disease categories } & \multirow[b]{2}{*}{ Case } & \multirow{2}{*}{$\begin{array}{c}\text { Adm. } \\
\text { days }\end{array}$} & \multicolumn{3}{|c|}{ Treatment amount (KRW) } \\
\hline & & & & $\begin{array}{l}\text { Insured } \\
\text { costs }\end{array}$ & $\begin{array}{l}\text { Patient sharing } \\
\text { of costs }\end{array}$ & All \\
\hline S03 & $\begin{array}{l}\text { Dislocation, sprain and strain of joints and } \\
\text { ligaments of head }\end{array}$ & 2 & 27 & $1,732,020$ & 588,605 & $2,320,625$ \\
\hline S04 & Injury of cranial nerves & 1 & 3 & 344,023 & 116,513 & 460,536 \\
\hline S06 & Intracranial injury & 5 & 175 & $23,108,870$ & $5,456,287$ & $28,565,157$ \\
\hline S12 & Fracture of neck & 1 & 4 & 499,432 & 166,477 & 665,909 \\
\hline S21 & Open wound of thorax & 1 & 30 & $5,340,466$ & $1,125,950$ & $6,466,416$ \\
\hline S22 & Fracture of rib(s), sternum and thoracic spine & 1 & 8 & 550,709 & 193,360 & 744,069 \\
\hline S23 & $\begin{array}{l}\text { Dislocation, sprain and strain of joints and } \\
\text { ligaments of thorax }\end{array}$ & 1 & 7 & 343,833 & 116,326 & 460,159 \\
\hline S32 & Fracture of lumbar spine and pelvis & 7 & 315 & $22,637,783$ & $8,054,659$ & $30,692,442$ \\
\hline S33 & $\begin{array}{l}\text { Dislocation, sprain and strain of joints and } \\
\text { ligaments of lumbar spine and pelvis }\end{array}$ & 1 & 3 & 141,627 & 47,315 & 188,942 \\
\hline S42 & Fracture of shoulder and upper arm & 1 & 5 & 590,047 & 174,251 & 764,298 \\
\hline S43 & $\begin{array}{l}\text { Dislocation, sprain and strain of joints and } \\
\text { ligaments of shoulder girdle }\end{array}$ & 2 & 23 & $1,453,538$ & 460,153 & $1,913,691$ \\
\hline S49 & $\begin{array}{l}\text { Other and unspecified injuries of shoulder and } \\
\text { upper arm }\end{array}$ & 1 & 30 & $4,458,716$ & $1,227,812$ & $5,686,528$ \\
\hline S52 & Fracture of forearm & 9 & 233 & $28,408,250$ & $8,481,260$ & $36,889,510$ \\
\hline S62 & Fracture at wrist and hand level & 2 & 40 & $3,762,624$ & $1,131,543$ & $4,894,167$ \\
\hline S72 & Fracture of femur & 6 & 331 & $34,382,429$ & $10,606,474$ & $44,988,903$ \\
\hline S73 & $\begin{array}{l}\text { Dislocation, sprain and strain of joint and } \\
\text { ligaments of hip }\end{array}$ & 1 & 30 & $1,956,758$ & 621,154 & $2,577,912$ \\
\hline S82 & Fracture of lower leg, including ankle & 1 & 60 & $5,225,640$ & $1,634,400$ & $6,860,040$ \\
\hline S83 & $\begin{array}{l}\text { Dislocation, sprain and strain of joints and } \\
\text { ligaments of knee }\end{array}$ & 1 & 3 & 341,303 & 102,207 & 443,510 \\
\hline T02 & Fractures involving multiple body regions & 2 & 14 & $1,626,585$ & 530,604 & $2,157,189$ \\
\hline Total & & 46 & 1,341 & $136,904,653$ & $40,835,350$ & $177,740,003$ \\
\hline Average & per case & - & 29.2 & 2,976,188 & 887,725 & $3,863,913$ \\
\hline Average & per admission day & - & - & 102,092 & 30,451 & 132,543 \\
\hline
\end{tabular}

ICD, International Classification Diseases; KRW, Korean won currency. 
Table 5. Medical benefits of outpatients based on ICD-10 codes (falls)

\begin{tabular}{|c|c|c|c|c|c|c|}
\hline \multirow{2}{*}{$\begin{array}{c}\text { ICD- } \\
10\end{array}$} & \multirow[b]{2}{*}{ Disease categories } & \multirow[b]{2}{*}{ Case } & \multirow{2}{*}{$\begin{array}{l}\text { Visit } \\
\text { days }\end{array}$} & \multicolumn{3}{|c|}{ Treatment amount (KRW) } \\
\hline & & & & $\begin{array}{l}\text { Insured } \\
\text { costs }\end{array}$ & $\begin{array}{c}\text { Patient sharing } \\
\text { of costs }\end{array}$ & All \\
\hline So0 & Superficial injury of head & 10 & 24 & 511,972 & 344,460 & 856,432 \\
\hline S01 & Open wound of head & 2 & 8 & 179,558 & 136,922 & 316,480 \\
\hline S02 & Fracture of skull and facial bones & 1 & 3 & 63,233 & 35,836 & 99,069 \\
\hline S03 & $\begin{array}{l}\text { Dislocation, sprain and strain of joints and } \\
\text { ligaments of head }\end{array}$ & 4 & 5 & 78,598 & 42,085 & 120,683 \\
\hline S06 & Intracranial injury & 1 & 13 & 603,205 & 564,994 & $1,168,199$ \\
\hline S12 & Fracture of neck & 1 & 3 & 75,109 & 73,754 & 148,863 \\
\hline S22 & Fracture of rib(s), sternum and thoracic spine & 2 & 7 & 153,320 & 89,543 & 242,863 \\
\hline S23 & $\begin{array}{l}\text { Dislocation, sprain and strain of joints and } \\
\text { ligaments of thorax }\end{array}$ & 6 & 59 & 958,666 & 404,229 & $1,362,895$ \\
\hline S29 & Other and unspecified injuries of thorax & 1 & 1 & 21,258 & 13,217 & 34,475 \\
\hline S30 & $\begin{array}{l}\text { Superficial injury of abdomen, lower back and } \\
\text { pelvis }\end{array}$ & 3 & 5 & 96,999 & 62,480 & 159,479 \\
\hline S31 & Open wound of abdomen, lower back and pelvis & 1 & 2 & 30,553 & 16,433 & 46,986 \\
\hline S32 & Fracture of lumbar spine and pelvis & 2 & 13 & 312,913 & 210,088 & 523,001 \\
\hline S33 & $\begin{array}{l}\text { Dislocation, sprain and strain of joints and } \\
\text { ligaments of lumbar spine and pelvis }\end{array}$ & 35 & 247 & $3,654,459$ & $1,535,264$ & $5,189,723$ \\
\hline S40 & Superficial injury of shoulder and upper arm & 1 & 2 & 37,782 & 24,614 & 62,396 \\
\hline S42 & Fracture of shoulder and upper arm & 1 & 6 & 124,554 & 89,215 & 213,769 \\
\hline S43 & $\begin{array}{l}\text { Dislocation, sprain and strain of joints and } \\
\text { ligaments of shoulder girdle }\end{array}$ & 5 & 46 & 681,741 & 329,262 & $1,011,003$ \\
\hline S50 & Superficial injury of forearm & 6 & 7 & 132,557 & 76,813 & 209,370 \\
\hline S51 & Superficial injury of forearm & 2 & 2 & 32,670 & 16,893 & 49,563 \\
\hline S52 & Fracture of forearm & 12 & 141 & $2,986,105$ & $1,832,781$ & $4,818,886$ \\
\hline S53 & $\begin{array}{l}\text { Dislocation, sprain and strain of joints and } \\
\text { ligaments of elbow }\end{array}$ & 15 & 124 & $2,544,722$ & $1,163,905$ & $3,708,627$ \\
\hline S60 & Superficial injury of wrist and hand & 2 & 3 & 55,801 & 31,727 & 87,528 \\
\hline S61 & Open wound of wrist and hand & 2 & 9 & 158,997 & 96,059 & 255,056 \\
\hline S62 & Fracture at wrist and hand level & 5 & 49 & 960,441 & 540,309 & $1,500,750$ \\
\hline S63 & $\begin{array}{l}\text { Dislocation, sprain and strain of joints and } \\
\text { ligaments at wrist and hand level }\end{array}$ & 15 & 68 & $1,191,921$ & 551,260 & $1,743,181$ \\
\hline S70 & Superficial injury of hip and thigh & 1 & 1 & 16,802 & 9,337 & 26,139 \\
\hline S72 & Fracture of femur & 8 & 75 & $1,499,607$ & $1,287,993$ & $2,787,600$ \\
\hline S73 & $\begin{array}{l}\text { Dislocation, sprain and strain of joint and } \\
\text { ligaments of hip }\end{array}$ & 25 & 99 & $1,505,132$ & 698,954 & $2,204,086$ \\
\hline S80 & Superficial injury of lower leg & 10 & 22 & 361,631 & 191,293 & 552,924 \\
\hline S81 & Open wound of lower leg & 4 & 16 & 250,017 & 130,482 & 380,499 \\
\hline S82 & Fracture of lower leg, including ankle & 2 & 15 & 298,927 & 185,427 & 484,354 \\
\hline S83 & $\begin{array}{l}\text { Dislocation, sprain and strain of joints and } \\
\text { ligaments of knee }\end{array}$ & 15 & 82 & $1,347,205$ & 691,461 & $2,038,666$ \\
\hline S90 & Superficial injury of ankle and foot & 1 & 1 & 18,852 & 10,916 & 29,768 \\
\hline S92 & Fracture of foot, except ankle & 3 & 25 & 548,563 & 294,032 & 842,595 \\
\hline
\end{tabular}


Table 5. Continued

\begin{tabular}{|c|c|c|c|c|c|c|}
\hline \multirow[b]{2}{*}{$\begin{array}{c}\text { ICD- } \\
10\end{array}$} & \multirow[b]{2}{*}{ Disease categories } & \multirow[b]{2}{*}{ Case } & \multirow{2}{*}{$\begin{array}{l}\text { Visit } \\
\text { days }\end{array}$} & \multicolumn{3}{|c|}{ Treatment amount (KRW) } \\
\hline & & & & $\begin{array}{l}\text { Insured } \\
\text { costs }\end{array}$ & $\begin{array}{l}\text { Patient sharing } \\
\text { of costs }\end{array}$ & All \\
\hline S93 & $\begin{array}{l}\text { Dislocation, sprain and strain of joints and } \\
\text { ligaments at ankle and foot level }\end{array}$ & 7 & 52 & $1,031,110$ & 511,238 & $1,542,348$ \\
\hline T00 & Superficial injuries involving multiple body regions & 1 & 1 & 18,736 & 12,421 & 31,157 \\
\hline T02 & Fractures involving multiple body regions & 6 & 82 & $2,475,252$ & $2,654,830$ & $5,130,082$ \\
\hline T03 & $\begin{array}{l}\text { Dislocations, sprains and strains involving multiple } \\
\text { body regions }\end{array}$ & 12 & 149 & $2,242,356$ & 880,879 & $3,123,235$ \\
\hline \multicolumn{2}{|l|}{ Total } & 230 & 1,467 & $27,261,324$ & $15,841,406$ & $43,102,730$ \\
\hline \multicolumn{2}{|c|}{ Average per case } & - & 6.4 & 118,528 & 68,876 & 187,403 \\
\hline \multicolumn{2}{|c|}{ Average per visit day } & - & - & 18,583 & 10,798 & 29,382 \\
\hline
\end{tabular}

ICD, International Classification Diseases; KRW, Korean won currency.

ment for fall-related injuries in the past year. As shown in Table 5, the total cost of medical benefits incurred by outpatients was $43,102,730 \mathrm{KRW}$, including insurance of $27,261,324 \mathrm{KRW}$ and patient cost-sharing of 15,841,406 KRW. The average outpatient cost was 187,403 KRW and the average patient cost-sharing was $68,876 \mathrm{KRW}$. The average daily outpatient fee was $29,382 \mathrm{KRW}$ and the average patient cost-sharing was 10,789 KRW. The total number of outpatient visits was 1,467 days, which involved 6.4 visits per case. Among outpatients, the highest cost of medical treatment according to ICD-10 code type was S33 (dislocation, sprain and strain of joints and ligaments of lumbar spine and pelvis), followed by T02 (fractures involving multiple body regions), S52 (fracture of forearm), S53 (dislocation, sprain and strain of joints and ligaments of elbow), T03 (dislocations, sprains and strains involving multiple body regions). The total hospitalization cost involving the first to fifth codes was 38,776,916 KRW, which accounted for $90.0 \%$ of total inpatient cost.

\section{Medical costs of oriental treatment}

The number of patients who visited outpatient clinics due to falls during the past year was 85 , the total number of visits was 347 , and the number of oriental treatments per case was 4.1. The calculated oriental treatment costs were 8,355,066 KRW based on the daily oriental clinic expenses of 24,078 KRW indicated in the 'Statistical Index of Medical Expenses in 2014' of the Health Insurance Review and Assessment Service.

\section{Medication costs}

In case of hospitalization, the cost of prescription drugs is included in the admission fee, and therefore, we did not calculate the inpatient drug fee separately. The total number of outpatients cases associated with falls in the past year was 230, and the total number of outpatient visits was 1,467 . However, among individuals sustaining falls during the past year, 152 visited only pharmacies directly, without consulting any professionals at medical institutions. The medication costs were calculated at $11,158,148 \mathrm{KRW}$ based on the daily medication expenses of 6,892 KRW indicated in the 'Statistical Index of Medical Expenses in 2014' of the Health Insurance Review and Assessment Service.

\section{Medical costs due to medical assistive equipment}

Of the 666 cases of fall reported during the past year, 60 utilized medical assistive equipment including 21 canes, 15 abdominal braces, 11 walkers, 8 joint supports, and 5 other devices. The purchase cost of these assistive devices according to the survey results amounted to a total of 2,755,000 KRW.

Total uninsured medical expenses and total direct costs The health care cost of the uninsured portion was calculated according to the 'Survey on the Benefit Coverage Rate of National Health Insurance in 2014' of NHIS. The uninsured portion of total medical expenses was $19.4 \%$ for hospitalization, $23.9 \%$ for outpatient clinic, and $30.3 \%$ for oriental medical clinic. Accordingly, the non-benefit costs were 42,781,093 KRW for hospital admissions, 
Table 6. Total direct costs $(n=2,012)$

\begin{tabular}{lccr}
\hline & $\begin{array}{c}\text { Benefit treatment } \\
\text { amount (KRW) }\end{array}$ & $\begin{array}{c}\text { Non-benefit treatment } \\
\text { amount (KRW) }\end{array}$ & Total (KRW) \\
\hline Inpatients & $177,740,003$ & $42,781,093$ & $220,521,096$ \\
Outpatient clinic & $43,102,730$ & $13,536,863$ & $56,639,593$ \\
Oriental clinic & $8,355,066$ & $3,632,116$ & $11,987,182$ \\
Medication & - & - & $11,158,148$ \\
Assistive equipment & - & - & $2,755,000$ \\
Total & & & $303,061,019$ \\
\hline
\end{tabular}

KRW, Korean won currency.

13,536,863 KRW for outpatient treatments, and 3,632,116 KRW for oriental treatments. The direct costs related to falls are calculated by adding the benefit and non-benefit costs. The total cost included 220,521,096 KRW involving hospital admission, 56,639,593 KRW covering outpatient treatment, 11,987,182 KRW for oriental treatment, 11,158,148 KRW for medications, and 2,755,000 KRW for medical assistive equipment, and the total direct costs related to falls sustained by 2,012 subjects were 303,061,019 KRW (Table 6). The average medical cost related to falls in the 2,012 subjects was $150,627 \mathrm{KRW}$ and the average medical costs of 666 subjects who experienced falls during the last year were 455,047 KRW.

Estimation of socioeconomic costs related to falls in the elderly

The total direct cost related to falls of 2,012 subjects was 303,061,019 KRW. According to the resident registration demographics available on the website of the Ministry of the Interior, as of December 2014, there are 9,147,370 people in Korea over 60 years of age. Estimates of the total population over the age of 60 years showed that annual direct medical costs associated with falls in Korea over the age of 60 years are about 1.378 trillion KRW.

\section{DISCUSSION}

In this study, $73.2 \%$ of the subjects experienced falls during their lifetime, and $33.1 \%$ of the falls occurred during the last year. These data are close to the annual $30.0 \%$ fall rate reported in a Western study [3]. The most frequent month for falls was December, was and they occurred outdoors, mostly in the afternoons. The most frequently reported cause was slippery floor, suggesting that a majority of falls occurred on roads with slippery ice during the winter and in the afternoon with a lot of activity. Increased awareness of the patterns of injury is needed to prevent falls.

Among the subjects, 666 experienced the incidents during the past year, and 566 of the subjects sustained injury as a result and 323 of them visit medical institutions for consultation or treatment. In other words, $16.1 \%$ of the total of 2,012 subjects visited medical institutions for fallrelated injuries and $57.1 \%$ of the 566 people who fell used medical facilities.

Fall-related injuries treated medically involved: low back $19.1 \%$, wrists and hands $12.5 \%$, hip $9.4 \%$, and elbow $9.1 \%$. The findings suggest that the most impact is applied to the back when a fall occurs. The high rate of damage to wrists and hands is related to the action of putting the hand on the floor during the fall. The types of injury were sprain $60.9 \%$ and fracture $21.6 \%$.

In this study, the socioeconomic costs associated with falls were estimated. The average medical costs of 666 subjects who experienced falls during the last year were $455,047 \mathrm{KRW}$. Therefore, if an elderly person sustains a fall, the average annual expense involved is 500,000 KRW, which is a significant economic burden for the elderly. The total direct cost for the 2,012 subjects was 303,061,019 KRW, amounting to a total of 1.378 trillion KRW in those aged 60 years or more. Therefore, falls in the elderly represent a great individual and socioeconomic burden.

The study limitation relates to the questionnaire-based format, and the results depend on the memories of the participants, suggesting a possible recall bias. In addition, since the survey involved the elderly who visited a public health center, the sample was not randomly selected. In addition, the medical expenses may be underestimated because it is impossible to include deaths due to falls and resulting complications. There may also be 
limitations in the methodology estimating the socioeconomic costs due to falls.

However, this large-scale study involved samples from the urban and rural areas to estimate the direct medical expenses due to falls in the elderly based on a questionnaire survey. A more accurate estimation may require additional items indicated in the national questionnaires such as the Community Health Survey.

The significance of this study relates to the development of an independent questionnaire to obtain objective and quantitative data related to geriatric falls. The study findings are expected to guide the development of medical policies and fall prevention programs for the elderly in Korea.

\section{CONFLICT OF INTEREST}

No potential conflict of interest relevant to this article was reported.

\section{ACKNOWLEDGMENTS}

This research was supported by the R\&D grant (No.
2015005) on rehabilitation by Korea National Rehabilitation Center Research Institute, Ministry of Health \& Welfare.

\section{REFERENCES}

1. Tinetti ME, Williams CS. Falls, injuries due to falls, and the risk of admission to a nursing home. N Engl J Med 1997;337:1279-84.

2. Reyes-Ortiz CA, Al Snih S, Markides KS. Falls among elderly persons in Latin America and the Caribbean and among elderly Mexican-Americans. Rev Panam Salud Publica 2005;17:362-9.

3. Grisso JA, Kelsey JL, Strom BL, Chiu GY, Maislin G, O'Brien LA, et al. Risk factors for falls as a cause of hip fracture in women. The Northeast Hip Fracture Study Group. N Engl J Med 1991;324:1326-31.

4. Franzoni S, Rozzini R, Boffelli S, Frisoni GB, Trabucchi M. Fear of falling in nursing home patients. Gerontology 1994;40:38-44.

5. Lee SG, Kam S. Incidence and estimation of socioeconomic costs of falls in the rural elderly population. J Korean Geriatr Soc 2011;15:8-19. 